\title{
JOGO LÚDICO COMO FERRAMENTA PEDAGÓGICA NA APRENDIZAGEM DE CONCEITOS QUÍMICOS
}

\author{
Cristiane Alves do Nascimento, Francisco Giovanni Ferreira dos Santos, \\ Rafaela Oliveira Freire, Paulo Gardel Torres de Sousa, \\ DrÁUlio SALES DA Silva \\ Universidade Estadual Vale do Acaraú - UVA \\ <chistiane100@hotmail.com>, <giovanni_fs2008@hotmail.com>, <rafinha-oliveira20@live.com>, \\ <gardeltorres@hotmail.com>, <draulio4000@yahoo.com.br>
}

DOI: $10.21439 /$ conexoes.v14i2.1303

\begin{abstract}
Resumo. As atividades lúdicas são consideradas educativas devido à maneira como auxiliam no desenvolvimento cognitivo necessário ao processo de aprendizagem, incluindo a resolução de problemas, estímulos responsáveis pela criatividade e raciocínio rápido, dentre outras habilidades. Pensando nisso, o presente artigo tem o objetivo de expor a utilização de um jogo lúdico como recurso metodológico para facilitar a aprendizagem e analisar o desenvolvimento do raciocínio e a construção do conhecimento de discentes no processo de ensino e aprendizado para alunos de $1^{\circ}$ ano do ensino médio sobre o conteúdo de distribuição eletrônica. Utilizou-se como meio de avaliar os alunos um questionário com questões objetivas e subjetivas que revelaram através de dados estatísticos que 94,50\% dos alunos conseguiram atingir os objetos propostos pelos bolsistas. Os resultados obtidos sugerem a importância da utilização dos jogos lúdicos pedagógicos no ensino.
\end{abstract}

Palavras-chaves: Ensino de Química. Jogo lúdico. Jogo didático. Ferramenta pedagógica.

\section{GAMIFICATION AS A TEACHING TOOL FOR LEARNING OF CHEMICAL CONCEPTS ABSTRACT}

\begin{abstract}
Play activities are considered educational because of the way they assist in the cognitive development necessary for the learning process, including problem solving, stimuli responsible for creativity and quick thinking, among other skills. With that in mind, this article aims to use of a playful game as a methodological resource to facilitate learning and analyze the development of reasoning and the construction of students' knowledge in the teaching and learning process for students of 1st year of high school on the content of electronic distribution. It was used a questionnaire with objective and subjective questions to assess the students. The results disclosed through statistical data that $94.50 \%$ of students have achieved the objects proposed by scholars, suggesting the importance of the use of educational fun games in teaching.
\end{abstract}

Keywords: Chemistry teaching. Playful game. Educational game. Pedagogical tool.

\section{INTRODUÇÃO}

O ensino de Química, assim como o ensino de outras ciências, tem se tornado um grande desafio para os docentes da área. Muitos alunos do Ensino Médio apresentam grandes dificuldades em compreender teorias e conceitos químicos. Uma das principais causas dessa dificuldade é o fato dos conteúdos ministrados não serem apresentados de forma harmonizada com a realidade do aluno. Pois na maioria das vezes o ensino de Química é retratado unicamente de uma forma considerada tradicional, onde apenas os pontos mais pertinentes dos conceitos são ensinados sem haver a dinamização de tal conteúdo, limitando-se a não fazer pontes com situações do dia-a-dia dos discentes.

Diante desta realidade, o aprendizado em Química acaba se tornando uma atividade cansativa e sem pertinências, instigando os estudantes a se questionarem acerca da finalidade de estarem estudando tal ciência, principalmente pela insistência de não apresentar para- 
lelos com situações cotidianas. Nesse contexto, Santos, Alves e Castro (2010) narram que "aprender Química torna-se, na maioria das vezes, uma tarefa exaustiva, trabalhosa e complicada, principalmente para os alunos que começam a introduzir esse conteúdo em seu cotidiano escolar".

Muitos professores ainda utilizam o ensino tradicional, tornando as aulas monótonas, cansativas e pouco produtivas. Pensando nisso, Rosa (2012)(p. 19), afirma que "a química deve ser transmitida num formato leve, em harmonia com suas vivências, despertando a curiosidade para os novos saberes químicos apresentados".

Nesse sentido, nos últimos anos tem aumentado significativamente a preocupação de romper com a monotonia e com o ensino tradicionalista, ocasionando a elaboração de novas metodologias que estimulem o interesse nos alunos. Além disso, intensificou-se a tentativa de optar por métodos de ensino mais acessíveis e com custo reduzido, desse modo, os jogos foram a escolha mais prática por atenderem estes requisitos.

O uso de novas ferramentas pedagógicas no ensino pode ser entendido como um meio de facilitar a aprendizagem, e nesse sentido o uso de jogos lúdicos auxilia bastante nos processos de ensino aplicados em sala de aula. A inclusão de jogo no ensino de Química pode incentivar e levar os alunos a uma construção do conhecimento mais significativa e representa uma quebra de paradigma com o ensino tradicional, exigindo que os alunos saiam do papel de espectadores e passem a ser sujeitos ativos na educação.

Os jogos didáticos se apresentam como uma metodologia mais atraente para ensinar conceitos normalmente pouco atrativos, facilitando ao aluno a memorização dos assuntos abordados em sala de aula e ajudando a induzi-lo ao raciocínio e a reflexão, e consequentemente a construção do conhecimento (DIAS, 2014)(p. 8).

O conteúdo que antes era de difícil compreensão dos alunos, torna-se mais atrativo com a utilização dos jogos didáticos, resultando em uma aprendizagem mais efetiva, facilitada pela maneira como é apresentado. $\mathrm{O}$ jogo passa a ser uma importante ferramenta a ser utilizada no âmbito escolar na medida em que estimula o interesse do aluno e desenvolve seu censo crítico, o ajudando a fazer novas descobertas.

Nesse contexto, é importante salientar que há diferença entre um jogo educativo e jogo didático, expressões comumente utilizadas e que ainda geram certa confusão entre educadores, pois "a educação é tida como uma atividade séria e controlada, enquanto que jogar lembra diversão ou simplesmente brincar" (CUNHA, 2012)(p. 95).
Ainda citando Cunha (2012)(p. 95), a autor explica a necessidade de compreender a importância de definir e diferenciar um jogo educativo de um jogo didático e destaca que:

O primeiro envolve ações ativas e dinâmicas, permitindo amplas ações na esfera corporal, cognitiva, afetiva e social do estudante, ações essas que devem ser orientadas pelo professor, podendo ocorrer em diversos locais. $\mathrm{O}$ segundo é aquele que está diretamente relacionado ao ensino de conceitos e/ou conteúdos, organizado com regras e atividades programadas e que mantém um equilíbrio entre a função lúdica e a função educativa do jogo, sendo, em geral, realizado na sala de aula ou no laboratório.

Diante disso, é importante também deixar claro a definição de jogo lúdico didático, pois, o jogo didático se constitui um importante recurso para o professor ao desenvolver nos alunos a capacidade de resolver problemas favorecendo a apropriação conceitos. Entretanto, em alguns casos são atribuídos conceitos equivocados sobre jogos lúdicos. Pensando nisso, (FERREIRA et al., 2012), narra que "uma atividade lúdica é todo e qualquer movimento que tem como objetivo produzir prazer quando de sua execução, ou seja, divertir o praticante". Se há regras, essa atividade lúdica pode ser considerada um jogo, pois estabelecem uma maior proximidade entre os participantes, contudo, é necessário que existam poucas regras e que sejam simples para evitar que o aluno se preocupe apenas com o jogo (ou pela diversão) deixando de lado o conteúdo da química abordado com sua utilização.

Para Cavalcanti e Soares (2007) Cavalcanti e Soares (2007) apud Soares (2008), quando a regra é adequadamente clara e seguida, o jogo, além de proporcionar aprendizado, pode-se mostrar uma excelente ferramenta de avaliação do conhecimento químico. Logo, para ser considerado um jogo educativo é preciso que desenvolva "habilidades cognitivas importantes para o processo de aprendizagem como, resolução de problemas, percepção, criatividade, raciocínio rápido, dentre outras habilidades" (ZANON; GUERREIRO; OLIVEIRA, 2008)(p. 73).

Este trabalho visa apresentar resultados da aplicação de um jogo lúdico utilizado como recurso metodológico para facilitar a aprendizagem e analisar o desenvolvimento do raciocínio e a construção do conhecimento de discentes no processo de ensino e aprendizado para alunos de $1^{\circ}$ ano do ensino médio sobre o conteúdo de distribuição eletrônica. 


\section{METODOLOGIA}

\subsection{A construção do objeto didático}

O jogo intitulado "Decifrando os símbolos químicos" foi uma ferramenta pedagógica elaborada para facilitar o trabalho de docentes no ensino do conteúdo sobre tabela periódica e distribuição eletrônica no ensino médio. Foi aplicado numa turma de $1^{\llbracket}$ ano, com 18 alunos da escola Centro Educacional de Referência Prefeito José Euclides Ferreira Gomes Júnior, parceira do Programa Institucional de Bolsas de Iniciação à Docência (PIBID), na cidade de Sobral - CE.

Inicialmente foram elaboradas as regras do jogo, em seguida, foi dada continuidade ao seu desenvolvimento confeccionando os materiais utilizados no mesmo.

O jogo "Decifrando os símbolos químicos" não envolveu todos os elementos da tabela periódica em decorrência do seu objetivo principal, ou seja, compreender o processo de distribuição eletrônica. Partindo desse pressuposto, entender sua relação com a organização dos elementos na tabela periódica. Diante disso, considerou-se desnecessário a utilização de todos os elementos, utilizando apenas 27 cartas onde cada uma representava um elemento químico. Em cada carta é exibido o número atômico do elemento químico e algumas informações eram solicitadas, ficando na responsabilidade dos jogadores participantes responderem, as cartas utilizadas podem ser vistas na Figura 1.

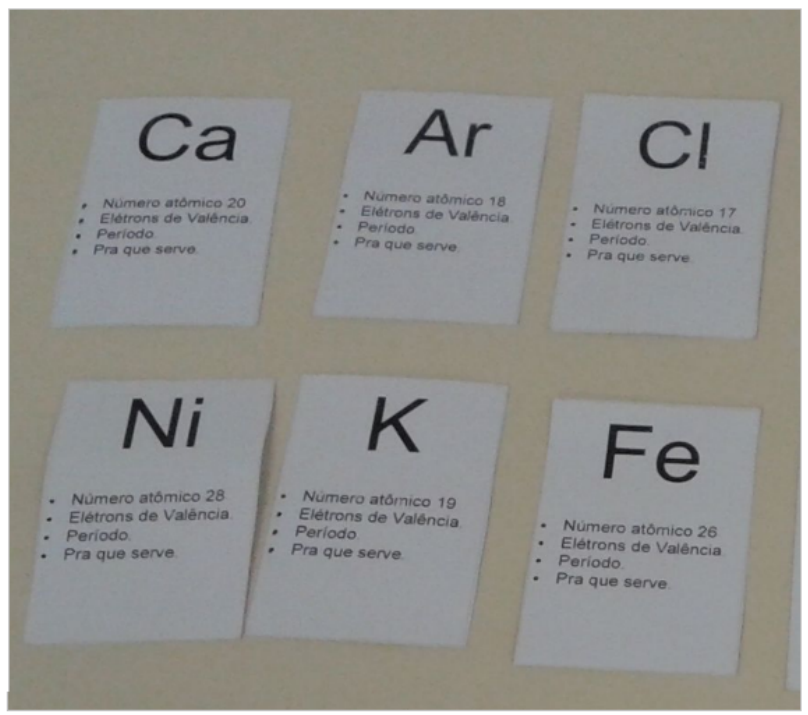

Figura 1: Cartas utilizadas no jogo

Fonte: Arquivo pessoal

O jogo foi desenvolvido para ser jogado por duas equipes, onde cada uma tinha o objetivo de localizar o elemento na tabela periódica. Para realizar esta tarefa, os alunos devem fazer a distribuição eletrônica, o que se dá de maneira mais rápida com a utilização de um diagrama de distribuição eletrônica, confeccionado pre- viamente conforme ilustrado na Figura 2. Outra tarefa do jogador é atribuir uma utilidade do elemento em seu cotidiano, atividade esta que proporciona aos alunos um aprendizado sobre a química de forma contextualizada e significativa.

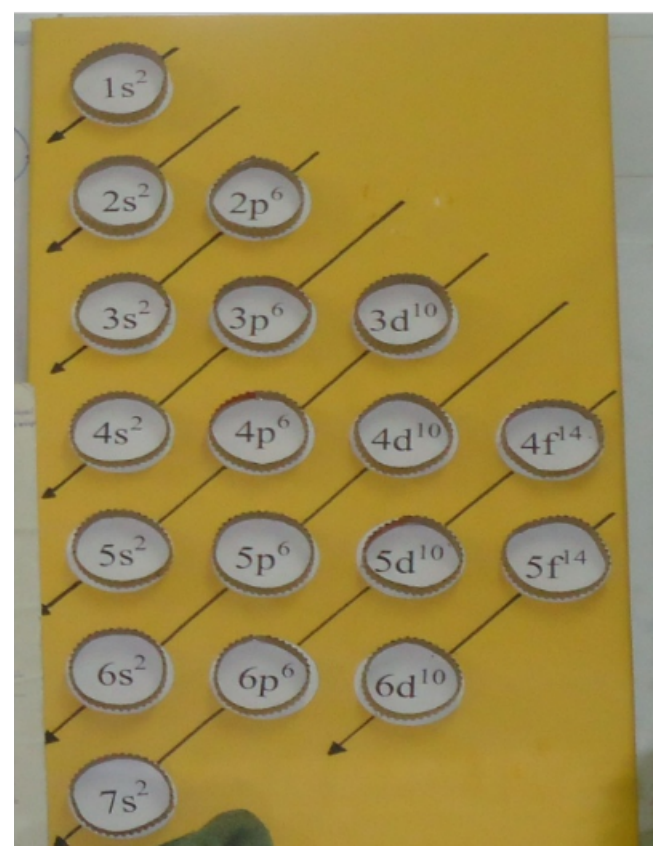

Figura 2: Diagrama de Pauling

Fonte: Arquivo pessoal

Ao término do jogo é atribuída a pontuação da equipe, que ocorre de acordo com cada subnível do diagrama preenchido corretamente (s, p, d, f), caso o elemento termine sua configuração eletrônica no subnível $s$, pontuará 5 pontos, no subnível $p, 10$ pontos, no subnível $d, 15$ pontos e no subnível $f 20$ pontos. A equipe vencedora será a que possuir maior pontuação.

\subsection{Aplicação do jogo}

A aplicação do jogo ocorreu dentro de uma sequência didática composta de três etapas. No primeiro momento foi estabelecida uma explanação sobre o conteúdo de distribuição eletrônica com os alunos, utilizando como recurso didático um quadro branco e uma tabela com o Diagrama de Pauling, onde se procurava identificar as principais dificuldades deles. No segundo momento acorreu a aplicação do jogo "Decifrando os símbolos químicos" e, na última etapa aplicou-se um questionário pós- aprendizagem para verificar a eficácia do jogo na absorção dos conhecimentos abordados e para conhecer a opinião dos alunos sobre a atividade realizada. 


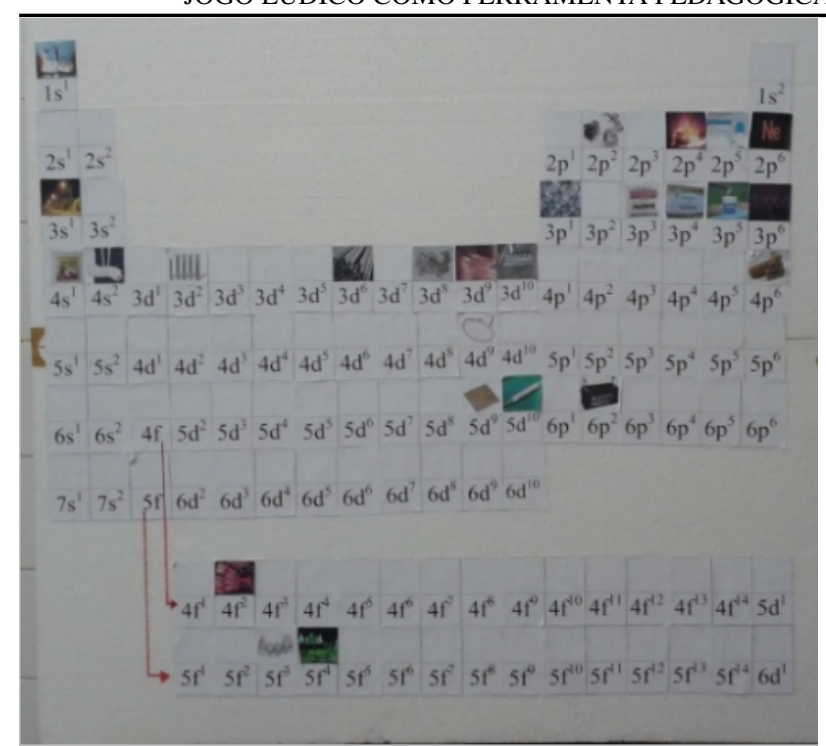

Figura 3: Tabela Periódica confeccionada para o jogo Fonte: Arquivo pessoal

\section{RESULTADOS E DISCUSSÃO}

\subsection{Importância do PIBID para o desenvolvimento do jogo}

O jogo foi desenvolvido por três bolsistas e um professor supervisor do Programa Institucional de Bolsas de Iniciação a Docência (PIBID). Este programa proporciona a inserção de estudantes de licenciaturas dentro da realidade escolar, oportunizando a vivência de situações concretas que efetivam e motivam a carreira docente através das experiências vivenciadas no programa (HILGEMANN et al., 2013).

Através do PIBID, a relação entre teoria e prática é constantemente discutida entre bolsistas e supervisor, possibilitando o desenvolvimento de recursos pedagógicos que facilitam o processo de ensino-aprendizagem de química como, por exemplo, a construção de jogos didáticos.

Outro aspecto importante no Programa é a oportunidade que os bolsistas assumem ao atuarem diretamente com as turmas, experienciando a docência e, em relação a isso, Frizon, Simão e Cigales (2017) narra que:

A oportunidade de desenvolver experiências pedagógicas, no contexto da realidade escolar, e a consequente interação com esse espaço influíram sobremaneira no aprendizado das futuras professoras, pois, ao mesmo tempo em que a realidade do campo de trabalho era desvelada, a escolha pela profissão era reafirmada (FRIZON; SIMãO; CIGALES, 2017)(p. 39).

Assim, na abordagem inicial, entre alunos e bolsistas, verificou-se uma relação importante de troca de co- nhecimentos propiciada na conversa investigativa com a utilização do Diagrama de Linnus Pauling, facilitando o desempenho da atividade, e logo, propiciando a oportunidade dos bolsistas desenvolverem e avaliarem a atividade com êxito, atingindo as metas propostas pelo Programa.

\subsection{Conhecendo as dificuldades dos alunos}

Esta foi a primeira etapa antes da aplicação do jogo propriamente dito. Neste momento foi possível verificar, através de uma conversa investigativa, o grau de dificuldade dos alunos sobre distribuição eletrônica, pois, durante a conversa era solicitado aos alunos que fossem voluntariamente ao quadro resolver alguns exemplos e, via-se então que mais da metade dos alunos demonstravam receio em resolver, pois ainda aparentemente apresentavam deficiências em relação ao assunto. Tais dificuldades podem ser justificadas pela maneira como o professor trata a disciplina, como apresenta os conceitos científicos em sala de aula, "muitas vezes é exigida memorização, reprodução de conceitos em detrimento da construção coletiva ou individualizada de conceitos científicos, acabando por desestimular os alunos" (BERGAMO, p. 9, 2012).

Pensando nessas dificuldades procurou-se abordar as principais dificuldades dos alunos, como o conhecimento sobre níveis e subníveis, assim como o reconhecimento do diagrama de Pauling com a ordem de distribuição eletrônica dos elementos, havendo uma participação mais efetiva dos alunos através de perguntas sobre o conteúdo abordado.

\subsection{Aplicação do jogo}

Durante a aplicação do jogo não foram encontradas muitas dificuldades em organizar os alunos para explicar as regras, todos se mostraram bastante empolgados para a realização do mesmo. Tal fato é justificado na ideia de que os jogos didáticos ao serem levados à sala proporcionam uma nova maneira dos estudantes adquirirem aprendizagem de conceitos possibilitando uma aprendizagem mais agradável, além de possibilitar o desenvolvimento de valores. Assim, ressalta-se a importância destes como ferramenta didática (CUNHA, 2012)(p. 96).

$\mathrm{Na}$ aplicação do jogo foram formadas duas equipes e entre cada equipe os alunos tinham que fazer a distribuição eletrônica dos elementos e responder as perguntas existentes nas cartas e, durante esse processo observavase que os alunos buscavam responder os questionamentos das cartas sempre contando com o apoio dos seus colegas de equipe, sempre unidos buscando vencer os adversários, demonstrando um companheirismo alunoaluno muito importante para o desenvolvimento cognitivo dos mesmos. Para Campos, Bortoloto e Felício 
(2003), os jogos favorecem a construção pelos alunos de seus próprios conhecimentos num trabalho em grupo.

O uso de jogos no ensino de Química mostra-se então, uma ferramenta pedagógica bastante eficaz por quebrar o modelo de ensino tradicional cumprindo a função de reforço do processo de ensino-aprendizado da disciplina.

\subsection{Aplicação do Questionário}

Após a aplicação do jogo os alunos receberam um questionário para avaliar se o jogo contribuiu para uma melhor compreensão de distribuição eletrônica e tabela periódica, sendo composto por duas questões discursivas e três questões objetivas.

Na questão de número 1 os alunos foram questionados sobre qual a ideia que eles possuíam sobre distribuição eletrônica após o uso do jogo. As respostas dos alunos foram avaliadas segundo duas categorias, conforme a tabela abaixo:

Tabela 1: Categorias e exemplos das respostas relacionadas à questão sobre o melhor entendimento das aulas de química sobre distribuição eletrônica com o uso de um jogo.

\begin{tabular}{l|l} 
Categorias & Respostas \\
\hline Compreenção & $\begin{array}{l}\text { "Conseguimos fazer a } \\
\text { distribuição dos elétrons de } \\
\text { forma mais fácil". }\end{array}$ \\
\hline Habilidade adquirida & $\begin{array}{l}\text { "O jogo ajudou a clarear } \\
\text { algumas dúvidas sobre alguns } \\
\text { elementos mais difíceis". }\end{array}$
\end{tabular}

Pode-se inferir através das respostas dos alunos que o jogo pode facilitar a compreensão do conteúdo abordado e permitiu que os mesmos adquirissem mais habilidade ao fazerem a distribuição eletrônica dos elementos. Segundo Campos, Bortoloto e Felício (2003), o jogo pode promover a construção do conhecimento cognitivo, físico, social e psicomotor, o que o leva a memorizar mais facilmente $\mathrm{o}$ assunto abordado.

Ao serem questionados, na questão de número 2, se após o jogo conseguiram fazer a distribuição eletrônica dos elementos com mais facilidade, $88,9 \%$ responderam que sim e apenas $11,1 \%$ responderam que não conseguiram. Também foi possível estabelecer uma conexão dos elementos da tabela periódica com o cotidiano dos alunos através da questão de número 3, onde os alunos foram questionados se o uso do jogo pode facilitar a identificação de elementos químicos no cotidiano, conforme apresentado no gráfico 1 a maioria dos alunos, 94,5\%, responderam que sim e citaram exemplos, Sim, uso de sódio em pastas de dentes e em lâmpadas, e apenas 1 aluno $(5,5 \%)$ disse não e sem justificativa.

Na questão de número 4, foi solicitado que os alunos identificassem através da distribuição eletrônica do elemento Sódio o período/camada, a subcamada e a quan-

\section{Após o jogo você consegue fazer a distribuição eletrônica dos elementos com mais facilidade?}

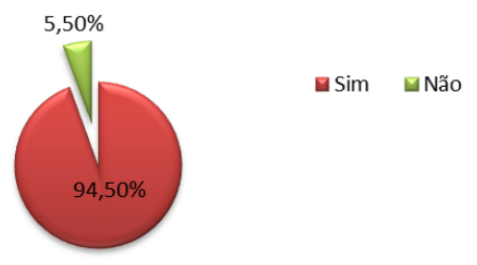

Figura 4: Tabela Periódica confeccionada para o jogo Fonte: Arquivo pessoal

tidade de elétrons que o elemento possuía na última camada. Podemos verificar através desta questão que a relação entre a configuração eletrônica de um elemento e a classificação de período/camadas da tabela periódica foi realmente compreendido pela maioria dos alunos que responderam à questão pois, 77,8\% responderam-na positivamente e apenas $22,2 \%$ disseram que não.

O jogo pode oferecer estímulo e o desenvolvimento espontâneo e criativo dos alunos, além de propiciar ao professor a ampliação de seus conhecimentos sobre técnicas de ensino desenvolvendo capacidades pessoais e profissionais, estimulando-o a recriar sua prática pedagógica (BRASIL, 2008).

Ao final do questionário, na questão de número 5 os alunos deveriam classificar o jogo. Apesar de 5,5\%, que representa apenas 1 aluno, ter considerado o jogo ruim foram obtidas uma maioria de respostas positivas pois, 10 alunos consideraram o jogo bom, representando $55,5 \%$ do total de alunos e os demais, $39 \%$, consideraram o jogo excelente, conforme podemos acompanhar no Gráfico 2, evidenciando que o uso do jogo foi muito importante para despertar nos alunos o interesse pelo conteúdo e pelo jogo melhorando, dessa forma o aprendizado dos alunos.

\section{Como você classifíaria este jogo?}

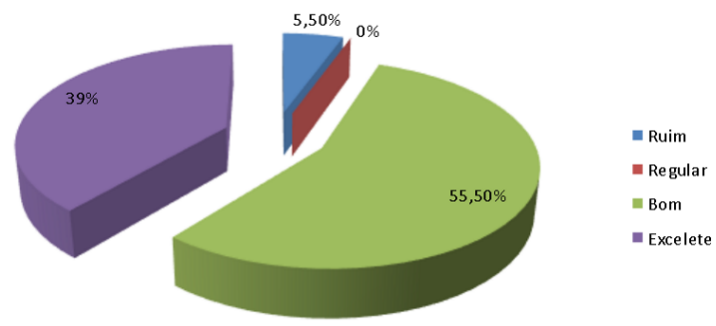

Figura 5: Tabela Periódica confeccionada para o jogo Fonte: Arquivo pessoal 
Embora uma minoria dos alunos tenha rejeitado o jogo, o mesmo pode atender às expectativas, pois, houve uma grande aceitação e interação entre os alunos durante todo o jogo.

O jogo proporciona a liberdade e não possui essa atmosfera de medo criada em sala de aula. O erro pode durante o jogo ser trabalhado de forma lúdica, sem pressão para o aluno e sem opressão por parte de colegas e professor, fazendo com que, o aluno tenha total liberdade para opinar, mostrar toda sua criatividade e interagir com os outros alunos e com o professor tentando solucionar os problemas de aprendizagem. (CAVALCANTI; SOARES, 2007)(p.261)

Dessa maneira, o uso de jogos torna-se bastante importante na construção do conhecimento e deve manterse como uma estratégia utilizada por professores no ensino de química, pois quebra o paradigma do ensino tradicional ainda bastante presente nas aulas de química.

\section{CONCLUSÃO}

Este trabalho mostra quão importante é a utilização de atividades que estimulam o aprendizado do aluno utilizando um jogo educativo, buscando ao mesmo tempo promover momentos de interação e convívio social entre os participantes, promovendo aprendizado através do jogo, não esquecendo a importância de manter o equilíbrio dos valores lúdico e didático da atividade.

A proposta de trabalhar com o lúdico proporcionou um resultado positivo, uma vez que os alunos ao terem contato com o conteúdo sobre distribuição eletrônica, na forma lúdica, utilizando conhecimentos prévios obtidos nas aulas com o professor titular da disciplina e da aula expositiva feita pelos bolsistas, conseguem abstrair do jogo alguns conhecimentos que lhes faltava. Os próprios alunos reconheceram a importância do uso de jogos lúdicos, sugerindo os mesmos como forma de melhorar o seu aprendizado na disciplina.

\section{AGRADECIMENTOS}

Os autores agradecem à Capes, pelo auxílio financeiro, à Universidade Estadual Vale do Acaraú-UVA e à Escola de Ensino Médio Prefeito José Euclides Ferreira Gomes Júnior.

\section{REFERÊNCIAS}

BRASIL, M. d. e. e. S. d. E. M. e. T. Orientações Educacionais Complementares aos Parâmetros Curriculares Nacionais: Ensino Médio: Ciências da Natureza, Matemáticas e suas Tecnologias. Brasília: MEC, 2008. v. 2.
CAMPOS, L. M. L.; BORTOLOTO, T. M.; FELíCIO,

A. K. C. Caderno dos núcleos de ensino. In:

[S.1.]: Botucatu, 2003. cap. A produção de jogos didáticos para o ensino de Ciências e Biologia: uma proposta para favorecer a aprendizagem, p. 35-48.

CAVALCANTI, E. L. D.; SOARES, M. H. F. B. O role playing game e o ensino de química. Revista Eletrônica de Ensenanza de las Ciências, 2007.

CUNHA, M. B. Jogos no ensino de química: Considerações teóricas para sua utilização em sala de aula. Química Nova na Escola, n. 2, maio 2012.

DIAS, E. d. F. Distribuição Eletrônica Dinâmica, um Recurso Didático para Aprendizagem de Química no Ensino Médio. Dissertação (Mestrado) — Trabalho de Conclusão de Curso (Licenciatura em Química), Universidade Estadual da Paraíba, UEPB, Campina Grande, 2014.

FERREIRA, E. A.; GODOI, T. R. A.; SILVA, L. G. M.; SILVA, T. P.; ALBUQUERQUE, A. V. Aplicação de jogos lúdicos para o ensino de química: auxílio nas aulas sobre tabela periódica. In: Anais do Encontro Nacional de Educação, Ciência e Tecnologia (UEPB). Campina Grande-PB: [s.n.], 2012.

FRIZON, L. M. B.; SIMãO, A. N. V.; CIGALES, J. R. Aprendizagens na docência: Pibid e a formação de professores. Revista e-Curriculum, São Paulo, v. 15, n. 1, p. $25-44,2017$.

HILGEMANN, C. M. et al. Vivências no pibid: Contribuições À formação docente. Revista Destaques Acadêmicos, CCHJ/UNIVATES, v. 5, n. 2, 2013.

ROSA, D. L. Aplicação de metodologias alternativas para uma aprendizagem significativa no ensino de química. Dissertação (Mestrado) - Monografia (Especialização em Ensino na Educação Básica) Departamento de Educação e Ciências Humanas do Centro Universitário Norte do Espírito Santo da Universidade Federal do Espírito Santo, 2012.

SANTOS, V. F.; ALVES, B. H. P.; CASTRO, L. M. d. Elaboraçção e aplpicação de jogos didáticos nas aulas de química no ensino fundamental e médio. Goiás: [s.n.], 2010. Instituto Federal de Educação, Ciência e Tecnologia de Goiás.

SOARES, M. H. F. B. Jogos e atividades lúdicas no ensino de química: teoria, métodos e aplicações. In: XIV Encontrro Nacional de Ensino de Química. Departamento de química da UFPR. [S.l.: s.n.], 2008.

ZANON, D. A. V.; GUERREIRO, M. A. S.;

OLIVEIRA, R. C. Jogo didático ludo químico para 
o ensino de nomenclatura dos compostos orgânicos: projeto, produção, aplicação e avaliação. Ciências $\boldsymbol{\&}$

Cognição, v. 13, n. 1, p. 72-81, 2008. Disponível em:

$<$ http://www.cienciasecognicao.org $>$. 